SECCIÓN ABIERTA 

REVISTA DE DERECHO UNED, NÚM. 13, 2013

\title{
LA PROTECCIÓN JURÍDICA DE LAS PERSONAS CON DISCAPACIDAD Y LAS NUEVAS TECNOLOGÍAS
}

\section{THE LEGAL PROTECTION OF DISABLED PERSONS AND THE NEW TECHNOLOGIES}

\author{
YVETTE VELARDE D’AMIL
}

Doctora en Derecho. Profesora de Derecho Civil CUNEF

Resumen: La irrupción de la denominada Sociedad de la Información, es un fenómeno que ha llegado a compararse con la Revolución Industrial, en cuanto a la transformación tan profunda que ha supuesto tanto en los esquemas de trabajo, como en los patrones de comportamiento sociales. Entre las múltiples aplicaciones de las nuevas tecnologías de la información, cabe destacar su utilidad como medio para facilitar la integración social de las personas con discapacidad. Esto es lo deseable y la tendencia en los foros nacionales e internacionales, pero la efectividad de tales propósitos, requiere la implementación de una serie de políticas públicas y de iniciativas privadas, que impidan que estas nuevas tecnologías, se constituyan en una nueva barrera que aumente las desigualdades sociales que separan a las personas discapacitadas, del resto de la población, teniendo que añadir a su discapacidad natural, su discapacidad digital.

Palabras clave: TIC, personas con discapacidad, discapacidad natural, discapacidad digital.

Abstract: The irruption of the so-called Information Society, constitutes a phenomenon which has been compared to the Industrial Revolution, with regard to the intense metamorphosis observed in the labour plans as well as in the social behavior patterns. Among 
the numerous applications of the modern data processing technologies, it's important to emphasize its usefulness as a vehicle to facilitate the social integration of disabled persons. This is the ideal situation and the topic orientation in national and international forums, but the effectiveness of such intentions demands the implementation of a sequence of public policies and private initiatives, intended to prevent these new technologies to become into another obstacle, which may increase the social differences that isolate disabled persons from the rest of the population; having, of course, to aggregate their digital disability to their natural disability.

Key words: ICT, disabled persons, natural disability, digital disability.

Recepción original: 01/11/2013

Aceptación original: 15/11/2013

La introducción en nuestra vida cotidiana, de la Sociedad de la Información y de las Nuevas Tecnologías que lleva asociada, ha supuesto una transformación tan profunda en los esquemas de trabajo y en los patrones de comportamiento sociales equiparables a los producidos por la Revolución Industrial.

Y ello, debido a que su incursión paulatina desde los años 80 del siglo pasado, ha revolucionado nuestra forma de comunicarnos, de estudiar, de investigar, de trabajar e incluso, de pensar. Estas nuevas tecnologías también han abierto posibilidades en todos los ámbitos, hasta hace pocos años inimaginables, algunas de éstas, casi de ciencia ficción.

Todo ello gracias a la inmediatez de las comunicaciones; a la accesibilidad de la información; a la precisión y exactitud de los datos, entre otras.

Sin embargo, para poder sacar el máximo partido al sinnúmero de posibilidades que ofrecen las nuevas Tecnologías de la Información y de la Comunicación, hace falta que el usuario tenga la formación y la capacitación necesaria y que desarrolle las destrezas que se requieran en los entornos digitales correspondientes.

Entre las múltiples aplicaciones de estas Nuevas Tecnologías, se ha demostrado su utilidad como medio para facilitar la integración social de las personas con discapacidad. 
Lo deseable sería que desde los poderes públicos se impulsaran políticas públicas para acercar y adaptar el entorno digital al colectivo integrado por las personas discapacitadas. De manera tal, que los beneficios que la aplicación de las Nuevas Tecnologías de la Información y de la Comunicación puedan aportarles, sean efectivas y les permitan un mayor grado de integración y de participación social.

Y que, por el contrario, no contribuyan a aumentar las desigualdades existentes entre las personas discapacitadas y el resto de la sociedad. Que no constituyan por sí mismas una causa adicional de discriminación.

Se ha acuñado el término brecha digital, para referirse a ese distanciamiento existente por un lado, entre aquella parte de la sociedad que por distintas circunstancias (medios económicos, nivel educativo, régimen político del país en el que vive, etc.), tiene acceso a la Sociedad de la Información y a sus tecnologías anejas, y que gracias a ello, dispone y disfruta ampliamente de todos sus ventajas; y por otro, el resto de la población, que se ve excluida de la sociedad digital.

En este sector desfavorecido por la brecha digital, se encuentra con carácter general, el colectivo discapacitado.

Y ello, debido a que el diseño de los propios sistemas necesarios para interactuar en el entorno digital, carecen de las herramientas y mecanismos que permitan la accesibilidad universal. Lastrando la posibilidad de acceso de los discapacitados en igualdad de condiciones que el resto de la sociedad, lo que supone una desigualdad agravada. Contribuyendo a ampliar la denominada brecha digital, aumentando la discriminación a la que se ven sometidos los discapacitados.

«La Brecha Digital, por desgracia, no es una nueva barrera, sino que es la constatación en formato electrónico, de unas sociedades que excluyen, discriminan y se despreocupan de si todos sus integrantes gozan o no de los avances del progreso humano...» (MORÁN CRIADO, J.M., «Tecnologías, conocimiento y Accesibilidad. El derecho de acceso de las personas con discapacidad a las tecnologías y al conocimiento colectivo» en «Hacia un Derecho de la Discapacidad. Estudios en Homenaje al profesor Rafael de Lorenzo» Fundación Academia Europea Yuste, Ed. ARANZADI, THOMSON REUTERS, 2009, pág. 792).

No obstante, las TICs deben considerarse como una oportunidad de acercamiento, como un medio de integración de las personas con 
discapacidad en las distintas parcelas de la vida social, contribuyendo a que salgan del aislamiento al que a menudo les destinan sus propias limitaciones naturales (físicas, psíquicas o sensoriales) no como un medio más de exclusión.

«Las personas con discapacidad tienen los mismos derechos que los demás ciudadanos, pero en la práctica, nuestras sociedades se organizan de una manera que suele impedir que estas personas disfruten de todos los derechos fundamentales: civiles, políticos, económicos, sociales y culturales. Éste es el motivo por el que la discapacidad es un aspecto de los derechos humanos y ello debería ser el punto de partida de toda política en la materia» (CABRA DE LUNA, M. A., «Las Leyes sobre Discapacidad y otras Leyes Sectoriales que afectan a las personas con discapacidad en el ámbito local» en «Entes Locales y Discapacidad», Ed. Centro de Estudios Municipales y Cooperación Internacional, Granada, 2009).

Desde esta perspectiva, un punto de inflexión en la promoción, reconocimiento y defensa de los derechos de las personas con discapacidad, ha sido la aprobación el 13 de diciembre de 2006, por la Asamblea General de las Naciones Unidas, de la Convención Internacional sobre los Derechos de las Personas con Discapacidad.

Y ello debido a distintas razones:

- Porque modifica la concepción tradicional de discapacidad, considerándola no como una minusvalía, sino como una parte más de la diversidad humana, que la enriquece. Se estima que el $10 \%$ de la población mundial, aproximadamente $650 \mathrm{mi}-$ llones de personas, posee algún tipo de discapacidad, o como lo que denomina la Convención: capacidades diferenciadas y diversidad funcional;

- Los discapacitados tienen derecho al reconocimiento y al respeto de su dignidad al igual que el resto de las personas no discapacitadas, aunque requieran de ayuda o de asistencia;

- Redefine y supera la perspectiva asistencial en la que se concibe a la persona con discapacidad como objeto de tratamiento y de protección social. Pasándose al pleno reconocimiento del discapacitado como sujeto titular de los derechos fundamentales en igualdad de condiciones que el resto de la sociedad y no sólo de los derechos sociales, como se ha venido haciendo tradicionalmente;

- Consagra el derecho a la accesibilidad universal;

- Incide en el cambio de mentalidad, para evitar que la limitación natural que padece el discapacitado se multiplique o se 
agrave, por la limitación social, esto es, por la forma en que el resto de la sociedad percibe la discapacidad en general;

- No pretende que se creen derechos nuevos que amparen a los discapacitados. Lo que persigue es que les sean reconocidos todos los derechos ya existentes pero en un plano de igualdad;

- Conseguir el respeto a los derechos humanos y a la dignidad de las personas discapacitadas dentro del marco amplio de los Derechos Humanos reconocidos por Naciones Unidas.

«La Convención es una norma coherente con el discurso contemporáneo de los derechos. Y ello se deduce claramente del examen de los principios que la inspiran, del enfoque que adopta a la hora de abordar la discapacidad, y de su alcance normativo». (DE ASIS, ROIG, R., "La Convención de la ONU como fuente de un nuevo Derecho de la Discapacidad» en «Hacia un Derecho de la Discapacidad. Estudios en Homenaje al profesor Rafael de Lorenzo» Fundación Academia Europea Yuste, Ed. ARANZADI, THOMSON REUTERS, primera ed. 2009, pág. 310).

La Convención de Nueva York, dota a la discapacidad de relevancia fundamental al atribuirle una Declaración de Derechos específica. Esta circunstancia le otorga fuerza normativa no sólo a nivel de cada uno de los Estados parte, que tienen la obligación de adecuar su ordenamiento jurídico interno a la letra y al espíritu de la Convención, sino también a nivel internacional, a través de la creación del Comité de los derechos de las personas con discapacidad, que es un órgano de expertos independientes que supervisa la aplicación de la Convención.

Igualmente, la Convención consagra tres tipos de deberes distintos que deberán cumplir los Estados parte, a saber:

- El deber de respetar los derechos de las personas con discapacidad, lo que supone la no injerencia en su vida privada, para no vulnerar otros derechos relacionados;

- El deber de proteger a las personas con discapacidad frente a la vulneración de sus derechos por parte de terceros; y,

- El deber de realizar todo tipo de medidas legislativas, administrativas, presupuestarias, judiciales y de cualquier índole, para garantizar el pleno ejercicio de estos derechos.

«La discapacidad es fundamentalmente un fenómeno social, no se trata simplemente de un problema médico que afecte de manera aislada a ciertos individuos, sino de un colectivo estructuralmente condenado a la marginación por la incapacidad de adaptación a sus necesidades por parte de la sociedad en la que viven, la discapaci- 
dad es impuesta por la sociedad, no es un atributo de la persona» (FERREIRA, M.A.V., "La construcción social de la discapacidad: hábitos, estereotipos y exclusión social», Nómadas, Revista Crítica de Ciencias Sociales y Jurídicas, N. ${ }^{\circ}$ 17, 2008, pág. 11).

La Convención de Nueva York, ha sido ratificada por España el 21 de abril de 2008 y entró en vigor, el 3 de mayo del mismo año.

Lo dispuesto en el párrafo $2 .^{\circ}$ del artículo 1 de la Convención sobre los Derechos de las Personas con Discapacidad, dice que «las personas con discapacidad incluyen a aquellas que tengan deficiencias físicas, mentales, intelectuales o sensoriales a largo plazo que, al interactuar con diversas barreras, puedan impedir su participación plena y efectiva en la sociedad, en igualdad de condiciones con los demás.»

Para dar cumplimiento a los fines de la Convención por parte de España, hará falta que se diseñen e implementen los mecanismos de cualquier índole, que contribuyan a eliminar los obstáculos y las barreras de todo tipo que aislan a las personas con discapacidad. Este aislamiento les impide que puedan integrarse en la sociedad, en igualdad de condiciones que el resto de la población, en la medida que les permitan sus condiciones personales.

Un primer paso para lograr una mayor equiparación con el resto de la sociedad, ha sido la adecuación de la normativa vigente en nuestro ordenamiento jurídico, en los distintos ámbitos que inciden directa e indirectamente en las personas con discapacidad, al tenor del contenido y espíritu de la Convención. Esto ha sido posible, mediante la promulgación de la Ley 26/2011, de 1 de agosto, de adaptación normativa a la Convención Internacional sobre los Derechos de las Personas con Discapacidad.

En el tema que nos ocupa, la Ley 26/2011, introduce un apartado nuevo a la disposición adicional quinta de la Ley 34/02, de 11 de junio, de servicios de la Sociedad de la Información y de Comercio Electrónico. Estableciendo la obligación de adaptación a los criterios de accesibilidad, para aquellas páginas de internet y para las redes sociales, cuando excedan de un determinado volumen anual de operaciones.

El derecho a la accesibilidad al entorno digital que tienen las personas discapacitadas, deberá rodearse de una serie de mecanismos que garanticen, que los datos personales que puedan suministrar, estén protegidos y que los contenidos a los que accedan no sean ilícitos ni puedan vulnerar su dignidad.

Al respecto, el artículo 18 de la Ley 34/2002, contempla la necesidad de que las Administraciones Públicas promuevan el diseño 
de códigos de conducta, en cuya elaboración deberán participar los representantes de las personas discapacitadas, para garantizar la licitud de sus contenidos.

Las personas discapacitadas tienen derecho a que se eliminen los obstáculos y las barreras de cualquier índole que les impidan acceder, en condiciones de igualdad a las nuevas tecnologías de la información y de la comunicación. Igualmente, les asiste el derecho de que se comercialicen a bajo coste las herramientas y los dispositivos que faciliten su adaptabilidad al entorno tecnológico, de acuerdo con su tipo y/o grado de discapacidad, cuando sus circunstancias personales lo permitan.

No obstante, es necesario que se arbitren las medidas de control y de protección jurídica de los derechos de la personalidad de estas personas, susceptibles de vulneración, en el cyberespacio.

En este sentido, la Ley Orgánica 1/1982, de 5 de mayo, de Protección Civil del Derecho al Honor, a la Intimidad Personal y Familiar y a la Propia Imagen, ya preveía en su artículo tercero, la posibilidad de que los discapacitados pudieran emitir su consentimiento directamente o a través de sus representantes legales, previo conocimiento del Ministerio Fiscal, para autorizar intromisiones en los derechos protegidos.

La Convención de Nueva York, consagra en su artículo 22, ese derecho a la privacidad, a la intimidad, al honor y a la reputación y la correlativa protección de la Ley contra injerencias arbitrarias o ilegales.

«En la lucha contra la discriminación de las personas con discapacidad sabemos por experiencia que la existencia de un marco legal adecuado es importante pero no suficiente. Las leyes sustantivas de atención a las personas con discapacidad en España han tenido menos dificultades en aprobarse que en ponerse en práctica, siendo frecuente su incumplimiento, en ocasiones impune.» (SASTRE CAMPO, A., «Mecanismos para la efectividad de la Convención de la ONU en España» en «Hacia un Derecho de la Discapacidad. Estudios en Homenaje al profesor Rafael de Lorenzo» Fundación Academia Europea Yuste, Ed. ARANZADI, THOMSON REUTERS, 2009, pág. 332).

La implementación del contenido normativo de la Convención ha tenido su primera manifestación en nuestro ordenamiento jurídico, a través de la Ley 26/2011, de 1 de agosto, de adaptación normativa a 
la Convención Internacional sobre los Derechos de las Personas con Discapacidad. No obstante, aún quedan aspectos pendientes.

En relación con este asunto, el Comité Español de Representantes de Personas con Discapacidad (CERMI) considera conveniente que en cualquier modificación del texto constitucional que se lleve a cabo, se incluya una necesaria adaptación al contenido y al espíritu de la Convención, en una serie de aspectos concretos:

- Con respecto al artículo 14 de la Constitución Española, «Los españoles son iguales ante la ley, sin que pueda prevalecer discriminación alguna por razón de nacimiento, raza, sexo, religión, opinión o cualquier otra condición o circunstancia personal o social.» Que se introduzca la discapacidad como una de las causas de discriminación, contrarias al principio de igualdad de todos los españoles, que se consagra en el artículo comentado;

- Que se adecue la terminología utilizada en el texto constitucional y con la que no se siente identificado el colectivo de las personas con discapacidad. Proponen, por consiguiente, que se sustituya el término;»disminuidos» empleado en el artículo 49, por el de discapacitados, "Los poderes públicos realizarán una política de prevención, tratamiento, rehabilitación e integración de los disminuidos físicos, sensoriales y psíquicos, a los que prestarán la atención especializada que requieran y los ampararán especialmente para el disfrute de los derechos que este Título otorga a todos los ciudadanos»;

- Consideran que el derecho a la inclusión y al bienestar deben formar parte del catálogo de derechos fundamentales consagrados en la Constitución Española, con la protección jurídica reforzada que les asiste, y no sólo como parte de los principios informadores de la política social y económica;

- Que sea competencia del Estado, no de las Comunidades Autónomas, garantizar el cumplimiento en todo el territorio nacional, de los derechos sociales, entre los que se encuentran los derechos reconocidos en el artículo 49. Plantean que se cumplan en igualdad de condiciones y en equidad, para todos los ciudadanos españoles que padezcan cualquier tipo de discapacidad.

La labor para lograr que desaparezca la invisibilidad con la que habitualmente se condena a las personas que poseen algún tipo de discapacidad, requerirá un trabajo continuo y en estrecha colaboración de los distintos agentes sociales,

- Las asociaciones representativas del colectivo de discapacitados, mediante su participación activa, proponiendo medidas 
nuevas y alternativas de mejora a las ya existentes, desde su conocimiento profundo y directo de las distintas necesidades del colectivo al que representan;

- Los poderes públicos, dando cumplimiento a lo dispuesto en el artículo 49 de la Constitución Española y en los Convenios y Tratados Internacionales ratificados por España, especialmente en la Convención de Nueva York, mediante el desarrollo normativo; la implementación de políticas de empleo, de incentivos fiscales para potenciar la contratación de personas con discapacidad; el apoyo a las familias de discapacitados mediante ayudas y potenciación de las políticas de apoyo a la dependencia; programas de integración y de inclusión desde la infancia; dotando de mayores medios económicos los programas destinados a los discapacitados; incentivando el abaratamiento de la adaptabilidad de las nuevas tecnologías de la información y de la comunicación, para que las personas discapacitadas puedan beneficiarse de la oportunidad digital, en igualdad de condiciones que el resto de la sociedad;

- El entorno empresarial, mediante la potenciación de programas de obra social y de empleo; potenciando políticas sociales de concientización y de respeto a la diversidad, que contribuyan a proyectar la imagen de las personas con discapacidad como una parte más de la diversidad de la humanidad, que facilite su integración social y laboral, reduciendo su marginación;

- La sociedad en general, es una labor de todos que debe consistir en un compromiso social de normalización, en un cambio de mentalidad a través de la educación. Reconociendo la discapacidad como parte de la variedad que enriquece a la humanidad en su conjunto y potenciando el respeto a la dignidad, a la igualdad de oportunidades, el derecho a beneficiarse de los avances tecnológicos en la comunicación y en la información.

Más de 650 millones de personas en todo el mundo; más de 3.8 millones, sólo en España, poseen algún tipo de discapacidad. La accesibilidad universal a las nuevas tecnologías de la información y de la comunicación es un derecho consagrado como tal, en la Convención Internacional sobre los Derechos de las Personas con Discapacidad. Además, es una oportunidad para gran parte de ellas, de acceder en la medida en que se lo permitan sus propias limitaciones, y en plano de igualdad con el resto de la sociedad, a todas las posibilidades que ofrece el cyberespacio.

Esto facilitaría su integración social y el ejercicio de todos los derechos humanos existentes y reconocidos y de los que también son sujetos titulares, las personas con discapacidad. 
Pero se requiere un importante cambio de mentalidad, un mayor grado de compromiso, de sensibilización y de concientización social, para lograr, con el esfuerzo de todos, que la Sociedad de la Información para Todos, deje de ser una entelequia y se convierta en una realidad enriquecedora para la humanidad en su conjunto.

\section{BIBLIOGRAFÍA}

CABRA DE LUNA, M. A., "Las Leyes sobre Discapacidad y otras Leyes Sectoriales que afectan a las personas con discapacidad en el ámbito local» en Entes Locales y Discapacidad, Ed. Centro de Estudios Municipales y Cooperación Internacional, Granada, 2009.

DE ASIS, ROIG, R., «La Convención de la ONU como fuente de un nuevo Derecho de la Discapacidad» en Hacia un Derecho de la Discapacidad. Estudios en Homenaje al profesor Rafael de Lorenzo, Fundación Academia Europea Yuste, Ed. ARANZADI, THOMSON REUTERS, 2009.

FERREIRA, M.A.V., «La construcción social de la discapacidad: hábitos, estereotipos y exclusión social», Nómadas, Revista Crítica de Ciencias Sociales y Jurídicas, n. ${ }^{\circ}$ 17, 2008.

MORÁN CRIADO, J.M., «Tecnologías, conocimiento y accesibilidad. El derecho de acceso de las personas con discapacidad a las tecnologías y al conocimiento colectivo» en Hacia un Derecho de la Discapacidad. Estudios en Homenaje al profesor Rafael de Lorenzo, Fundación Academia Europea Yuste, Ed. ARANZADI, THOMSON REUTERS, 2009.

SASTRE CAMPO, A., "Mecanismos para la efectividad de la Convención de la ONU en España» en Hacia un Derecho de la Discapacidad. Estudios en Homenaje al profesor Rafael de Lorenzo Fundación Academia Europea Yuste, Ed. ARANZADI, THOMSON REUTERS, 2009. 